\title{
TCTP protects from apoptotic cell death by antagonizing bax function
}

\author{
L Susini ${ }^{1,6}$, S Besse ${ }^{1,6}$, D Duflaut ${ }^{1,6}$, A Lespagnol ${ }^{1,6}$, C Beekman ${ }^{2,6}$, G Fiucci ${ }^{1}$, AR Atkinson ${ }^{3}$, D Busso ${ }^{3}$, P Poussin ${ }^{3}$, J-C Marine ${ }^{2}$, \\ J-C Martinou ${ }^{4}$, J Cavarelli ${ }^{3}$, D Moras ${ }^{3}$, R Amson ${ }^{1,5}$ and A Telerman ${ }^{\star, 1,5}$
}

Translationally controlled tumor protein (TCTP) is a potential target for cancer therapy. It functions as a growth regulating protein implicated in the TSC1-TSC2 -mTOR pathway or a guanine nucleotide dissociation inhibitor for the elongation factors EF1A and EF1B $\beta$. Accumulating evidence indicates that TCTP also functions as an antiapoptotic protein, through a hitherto unknown mechanism. In keeping with this, we show here that loss of tctp expression in mice leads to increased spontaneous apoptosis during embryogenesis and causes lethality between E6.5 and E9.5. To gain further mechanistic insights into this apoptotic function, we solved and refined the crystal structure of human TCTP at $2.0 \mathrm{~A}$ resolution. We found a structural similarity between the $\mathrm{H} 2-\mathrm{H} 3$ helices of TCTP and the $\mathrm{H} 5-\mathrm{H} 6$ helices of Bax, which have been previously implicated in regulating the mitochondrial membrane permeability during apoptosis. By site-directed mutagenesis we establish the relevance of the $\mathrm{H} 2-\mathrm{H} 3 \mathrm{Helices}$ in TCTP's antiapoptotic function. Finally, we show that TCTP antagonizes apoptosis by inserting into the mitochondrial membrane and inhibiting Bax dimerization. Together, these data therefore further confirm the antiapoptotic role of TCTP in vivo and provide new mechanistic insights into this key function of TCTP.

Cell Death and Differentiation (2008) 15, 1211-1220; doi:10.1038/cdd.2008.18; published online 15 February 2008

Inhibition of apoptosis plays a key role in permitting and favoring cell proliferation in malignant tissues. ${ }^{1}$ The characterization of proteins that promote or inhibit apoptosis, and the identification of their mechanism of action, constitute an important step towards the understanding of programmed cell death as a biological process and its implication in diseases. Recently, translationally controlled tumor protein (TCTP) has been suggested to function as an antiapoptotic protein in cultured cells. ${ }^{2-7}$ Overexpression of TCTP resulted in an inhibition of etoposide-induced apoptosis, ${ }^{3}$ whereas antisense and siRNA knockdown experiments resulted in increased apoptosis. ${ }^{5,7}$ It was more recently shown that TCTP binds to $\mathrm{MCL}^{2,4,7}$ and $\mathrm{BCl}-\mathrm{xL}^{6}{ }^{6}$ both antiapoptotic members of the $\mathrm{Bcl} 2$ family. However, the physiological relevance of these data in vivo and the molecular mechanisms through which TCTP protects cells from apoptosis remain to be established. TCTP shares no sequence homology with known antiapoptotic molecules nor it exhibits structural features that could account for such an antiapoptotic function.

TCTP is highly conserved in all eukaryotes and encodes for a hydrophilic protein of $18-23 \mathrm{kDa}^{8,9}$ that shows no sequence similarity with any other known proteins. TCTP was discovered over 20 years ago in Ehrlich acites tumor cells. ${ }^{10}$ Its name originates from the observation that TCTP transcripts accumulate in resting cells and are rapidly translated into the protein when the cells require it. The TCTP protein is expressed at low levels in resting cells, and at elevated levels in proliferating ones. TCTP expression in proliferating yeast (Saccharomyces cerevisiae (S.cerevisiae)) rises for instance to 100000 copies per cell, which is higher than actin with 60000 copies per cell. ${ }^{11}$ These data, in addition to very recent genetic studies, suggest that beside its antiapoptotic function TCTP may be required for cell growth and proliferation. For instance, Drosophila TCTP was shown to control cell growth and proliferation through regulation of Rheb-GTPase activity. ${ }^{12}$ In addition to its role in the control of cell survival and proliferation, TCTP was also reported to bind tubulin, ${ }^{13}$ to serve as a substrate of Polo-like kinase 1 (Plk1) ${ }^{14}$ and to act as a histamine releasing factor. ${ }^{15}$

TCTP is overexpressed in most tumor cells and its downregulation decreases the viability of those cells. ${ }^{5}$ Understanding the molecular mechanisms through which TCTP acts as a pro-survival factor in normal and cancer cells is therefore not only an interesting biological issue but it is also relevant for cancer therapy. ${ }^{16}$ In the present work, we show that TCTP

${ }^{1}$ Molecular Engines Laboratories, 20 rue Bouvier, Paris, France; ${ }^{2}$ Laboratory for Molecular Cancer Biology, VIB-UGent, Technologiepark, Ghent, Belgium; ${ }^{3}$ Département de Biologie et Génomique Structurales, UMR 7104, Institut de Génétique et de Biologie Moléculaire et Cellulaire, CNRS/INSERM/ULP Strasbourg, 1 rue Laurent Fries, IIIkirch, France and ${ }^{4}$ Department of Cell Biology, University of Geneva, Quai Ernest-Ansermet 30, Geneva, Switzerland

*Corresponding author: A Telerman, LBPA UMR 8113, École Normale Supérieure, 61 Avenue du Président Wilson, 94235 Cachan, France. Tel: + $33-62089$ 13 82; Fax: + 33-1 474076 71; E-mail: adam.telerman@ @lbpa.ens-cachan.fr and telerman@noos.fr

${ }^{5}$ Present address: Laboratoire de Biotechnologie et Pharmacologie génétique Appliquée (LBPA) UMR 8113, École Normale Supérieure, 61 Avenue du Président Wilson, 94235 Cachan, France.

${ }^{6}$ These authors contributed equally to this paper.

Keywords: TCTP; mitochondria; TCTP knockout mice

Abbreviations: TCTP, translationally controlled tumor protein; MEFs, mouse embryo fibroblasts; PARP, poly (ADP-ribose) polymerase; TUNEL, terminal deoxynucleotidyl transferase-mediated dUTP nick end-labeling; IVT, in vitro translation; TSC, tuberous sclerosis complex

Received 24.10.07; revised 10.1.08; accepted 14.1.08; Edited by KH Vousden; published online 15.2.08 
functions as an antiapoptotic protein required for mouse embryonic development. Moreover, we solved the crystal structure of TCTP and found an interesting structural similarity to channel-forming helices ${ }^{17}$ of the pro-apoptotic protein Bax. ${ }^{18}$ This led us to explore one of the potential mechanism by which TCTP exerts its antiapoptotic function and to propose that this is occurring by insertion of TCTP into the mitochondrial membrane and inhibiting the dimerization of Bax.

\section{Results}

tctp is required for cell survival and mouse embryonic development. The murine tctp gene is located on chromosome 14 and contains 6 exons. ${ }^{19}$ To generate a tctp mutant mouse line, a loxP site was inserted $5^{\prime}$ of exon 3 and two loxP sites flanking a neomycin resistance gene were inserted $3^{\prime}$ of exon 5 by homologous recombination in

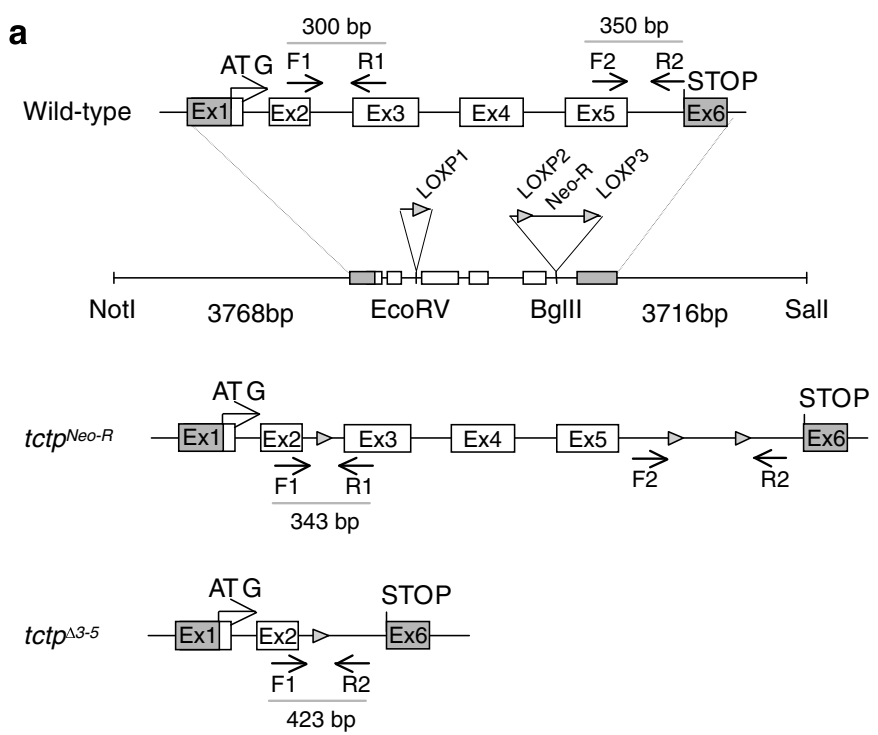

b

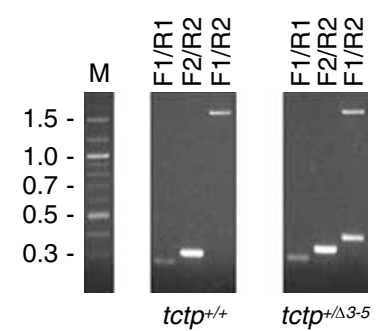

C

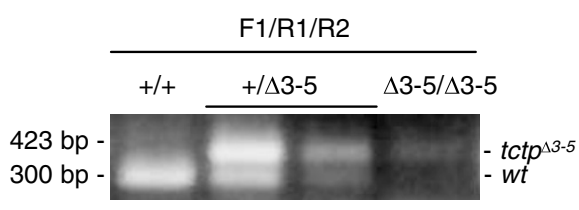

d

E9.5

E8.5

E7.5

e
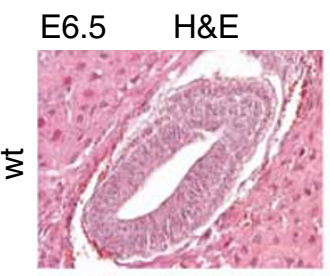

TUNEL/DAPI
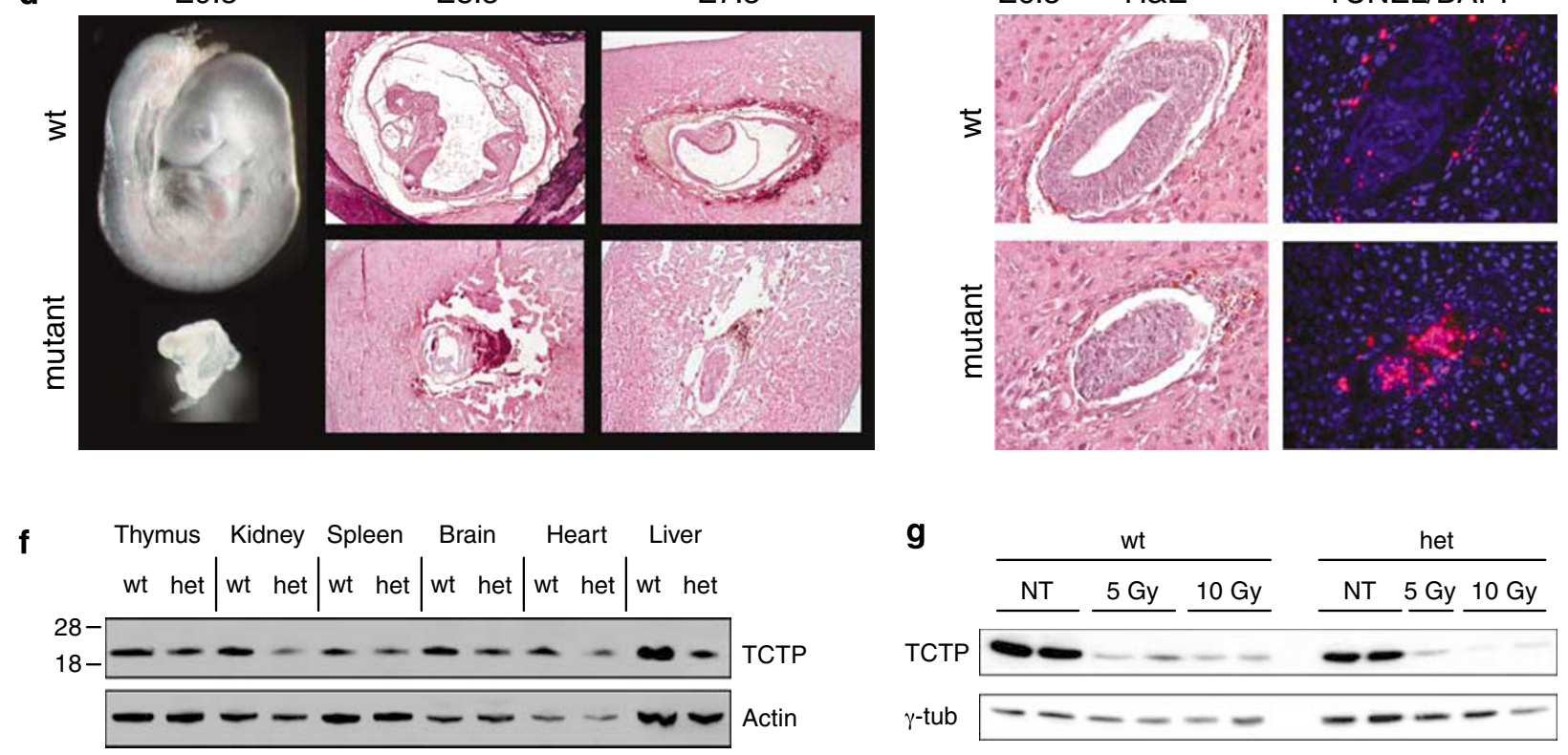

Figure 1 (a) Representation of the mouse wild-type and mutated tctp alleles and the targeting vector used to generate these alleles. F1, R1, F2, and R2 indicate the positions of the primers used to discriminate between the various tctp alleles (see $\mathbf{b}$ and $\mathbf{c}$ ). (b) PCR analysis on genomic DNA from wild-type (WT) and tctp heterozygous $(+/ \Delta 3-5)$ mice. The various primers used for the different PCRs are indicated (see Materials and Methods for their sequences) (c) PCR analysis on genomic DNA from wild-type $(+/+)$ and tctp heterozygous $(+/ \Delta 3-5)$ and homozygous mutant $(\Delta 3-5 / \Delta 3-5)$ embryos. (d) tctp-wild-type and -mutant embryos at different stages of development. Hematoxylin-eosin staining of sections of paraffin-embedded E8.5 and E7.5 embryos are shown. Magnification: $\times 4$. (e) Hematoxylin-eosin (H\&E) staining of sections of paraffin-embedded E6.5 embryos is shown. Detection of apoptotic cells (red) was performed using TUNEL assay on sections of paraffin-embedded E6.5 embryos; the sections were counterstained using DAPI (blue). Magnification: $\times 20$. (f) Western blot analysis of TCTP protein expression in different organs ( $30 \mu \mathrm{g}$ protein loaded) from wild-type (wt) and tctp heterozygous (het) mice; anti-Actin is used as loading control. (g) TCTP protein levels as determined by western blotting in freshly isolated thymocytes from wild-type (wt) and tctp heterozygous (het) mice. The cells were either left untreated (NT) or were $\gamma$-irradiated with 5 Gy or 10 Gy. Lysates were prepared $12 \mathrm{~h}$ after irradiation. Anti- $\gamma$-tubulin $(\gamma$-tub) is used here as loading control 
embryonic stem (ES) cells (Figure 1a). Correctly targeted ES clones $\left(t c t p^{N e o-R /+}\right.$ ) were obtained, as assessed by PCR and Southern blot, and Cre-mediated excision of exons 3-5, which encodes for most of the tctp protein, was achieved upon electroporation of a Cre-recombinase expression vector in those cells. One clone that showed proper deletion of exons 3-5 (tctp $\left.{ }^{\Delta-5 /+}\right)$, as identified by PCR analysis, was used to establish a tctp mutant mouse line. Mice were genotyped using a PCR-based approach using primers F1, R1, F2, and R2 (Figure $1 \mathrm{~b}$ and $\mathrm{c}$ ).

Heterozygous mice for this mutation $\left(\operatorname{tctp}^{\Delta 3-5 /+}\right)$ are viable and fertile. However, matings between heterozygous animals produced no viable homozygous mutant offspring (F2), indicating a recessive lethal phenotype (Supplementary Table 1).

Closer inspection revealed that most homozygous embryos $\left(\right.$ tctp $\left.^{\Delta 3-5 / \Delta 3-5}\right)$ died in utero between 6.5 and 9.5 d.p.c. The majority of the E6.5 and $100 \%$ of the E7.5 tctp-mutants exhibited an overall growth deficiency, ranging from minor to extremely severe (Figure 1d and e). No viable mutants were observed beyond E9.5 (Supplementary Table 1).

To study the effect of the tctp mutation on cellular proliferation, we measured in situ incorporation of 5-bromo2 -deoxyuridine and expression levels of a phosphorylated form of histone $\mathrm{H} 3$, a marker of mitosis by immunohistochemistry. The data indicate that the tctp-mutant cells proliferate to a lesser extent compared to cells of the control embryos (not shown). To determine if the growth deficit of tctp-mutant embryos could also be accounted for by an excess of apoptosis, serially sectioned E6.5 embryos were analyzed by immunohistochemistry using an antibody specific to the cleaved form of caspase-3 (not shown) and TUNEL analysis (Figure 1e). These analyses revealed extensive cell death in the developing mutant embryos.

Western blot analysis using anti-TCTP antibodies detects only one band at the expected molecular weight in protein lysates from mouse embryo fibroblasts (MEFs) (not shown) and various mouse organs (Figure 1f). In the lysates of tctp ${ }^{\Delta-5 /+}$ (het) animals, the TCTP signal is weaker in intensity, indicating that the tctp protein is expressed at lower levels in heterozygous tissues as compared to wildtype (wt) tissues (Figure 1f).

To test whether tctp is haploinsufficient in the control of cell proliferation and/or apoptosis, we next measured the cell proliferation capacity and/or the apoptotic response of MEFs and thymocytes prepared from wildtype and heterozygous tctp-mutants to various stress conditions. tctp $^{\Delta 3-5 /+}$ MEFs proliferated at the same rate in culture and underwent senescence similarly to wildtype controls (not shown). They also exhibited a similar cell cycle distribution and apoptotic response upon UV-C or doxorubicin exposure (not shown). We next measured apoptosis in freshly isolated thymocytes after $\gamma$-irradiation and dexamethasone (Dex) treatment. Susceptibility to cell death following DNA-damage in these cells is p53-dependent, whereas apoptosis in response to glucocorticoids (such as Dex) occurs independently of p53. Again, wild-type and heterozygous thymocytes were similarly sensitive to these treatments (not shown). Interestingly, however, we noticed a significant and dose-dependent decrease in TCTP levels in these cells following $\gamma$-irradiation (Figure 1g). Together, the data indicate that tctp is required for the survival and proper proliferation of cells during mouse embryonic development. Even if tctp levels are reduced in cells from heterozygous mice, tctp is not haploinsufficient in the control of cell proliferation and apoptosis. Finally, in response to DNA-damage, tctp steady state protein levels dramatically decrease in primary thymocytes, concomitantly with the onset of apoptosis.

The three-dimensional structure of human TCTP. The $X$-ray structure of human TCTP has been solved and refined at $2.0 \AA$ resolution (Supplementary Table 2 ). Phases were obtained by molecular replacement, using the coordinates of Schizosaccharomyces pombe (S.pombe) TCTP (PDB code: $1 \mathrm{H} 7 \mathrm{Y})$ as a probe. The crystallographic asymmetric unit contained four TCTP molecules and 508 water molecules. The X-ray structure of human TCTP confirms a common TCTP fold described previously for $S$. pombe TCTP. ${ }^{20}$ The structure contains three $\alpha$-helices $(\mathrm{H} 1, \mathrm{H} 2, \mathrm{H} 3)$ and nine $\beta$-strands arranged in two distorted $\beta$-sheets, forming two hydrophobic cores (Figure 2). A $\alpha$-helical hairpin is formed by the two long helices $\mathrm{H} 2$ and $\mathrm{H} 3$ and protects one face of the central $\beta$-sheet. In each subunit, a polypeptide encompassing residues $39-66$ is not visible in the electron density map, but certainly protrudes out of the opposite side of the core $\beta$-sheet and is presumed to be disordered. In $S$. pombe TCTP, this portion was shown by NMR spectroscopy to be highly mobile. ${ }^{21}$ As noted previously, the TCTP fold has structural similarities with two other proteins: the guanine nucleotide-free chaperone Mss4 ${ }^{20}$ and the methionine sulfoxide reductase gene $\mathrm{B}(\mathrm{MsrB}) .{ }^{22}$ However, the biological significance of these structural similarities remains unclear.

Comparison of the structure of human TCTP with those of proteins in the Protein Data Bank using DALI yielded a number of other interesting similarities. In particular, the pair of helices $\mathrm{H} 2-\mathrm{H} 3$ bear structural resemblance to the transmembrane domains of diphtheria toxin and bacterial colicins $^{23}$ and to the pair of helices $\mathrm{H} 5-\mathrm{H} 6$ in Bcl2 family proteins ${ }^{17,24-27}$ such as Bax, ${ }^{18}$ despite negligible amino acid homology. It should be noted that there is no striking amino acid homology between the members of the $\mathrm{Bcl} 2$ family in the domain encompassing these $\mathrm{H} 5-\mathrm{H} 6$ (or H6-H7) pore-forming helices but, only a structural similarity.

Besides these two helices, the rest of the protein structure of the Bcl2 family members, including the Bcl2 Homology domains, fit within a common fold, which is not the case for TCTP.

Mutations in helices H2-H3 of human TCTP modify its antiapoptotic function. To investigate whether helices $\mathrm{H} 2-\mathrm{H} 3$ participate in the antiapoptotic function of TCTP, 293T cells were first incubated in the presence of staurosporine, and the levels of TUNEL-positive cells and the extent of PARP cleavage were monitored. TCTP decreases both the levels of TUNEL-positive cells (Figure $3 a$ ) and the extent of PARP cleavage (Figure $3 b$ ) induced by staurosporine. Strikingly, TCTP also significantly inhibits Bax-induced apoptosis in 293T cells (Figures 3b and d-f) and in N2A cells (data not shown). 

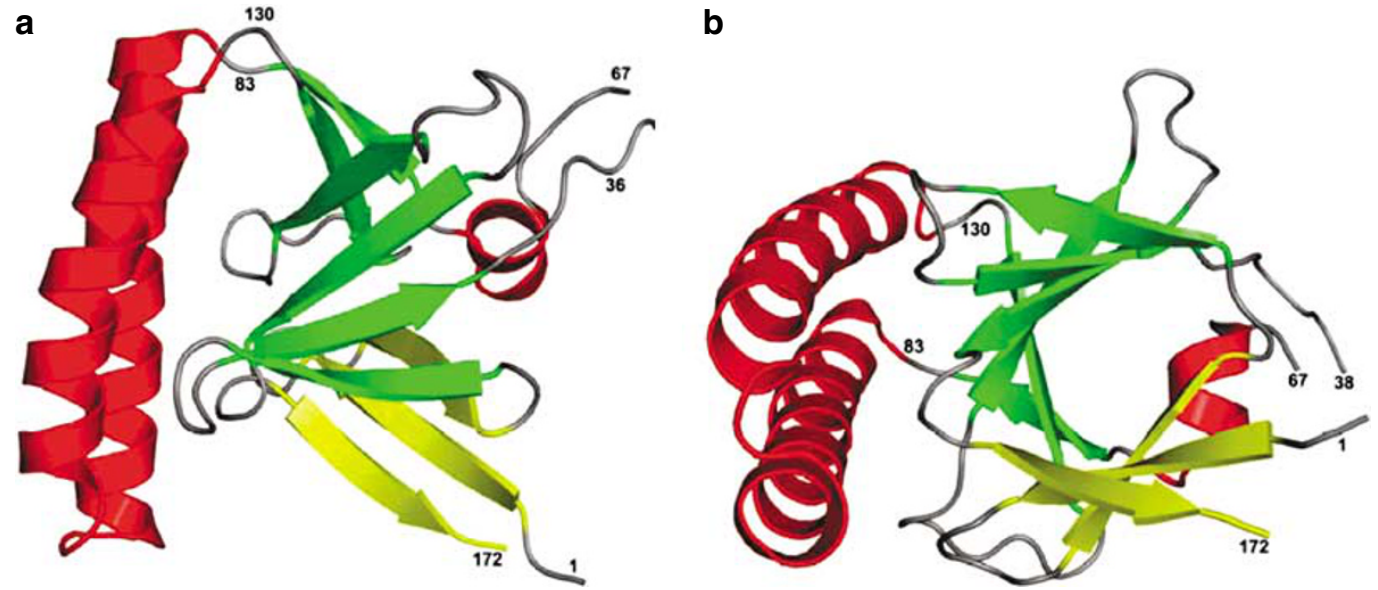

Figure 2 The crystal structure of human TCTP. Two different orientations $(\mathbf{a}, \mathbf{b})$ of the molecule are presented showing the two distorted $\beta$-sheets in green and yellow and the three $\alpha$-helices in red. Residues 39-66 belong to a highly mobile polypeptide segment and are not visible in the final electron density map

a

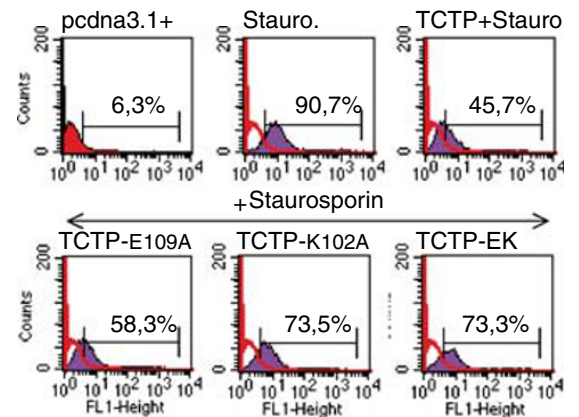

b

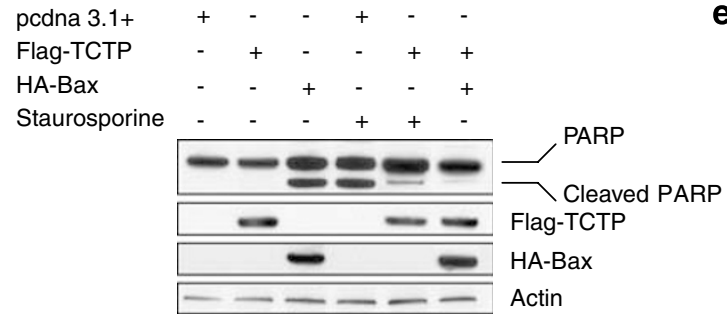

C

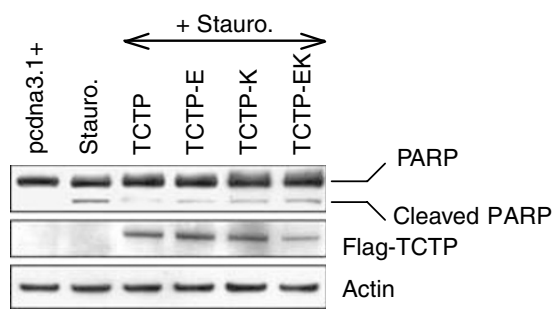

d
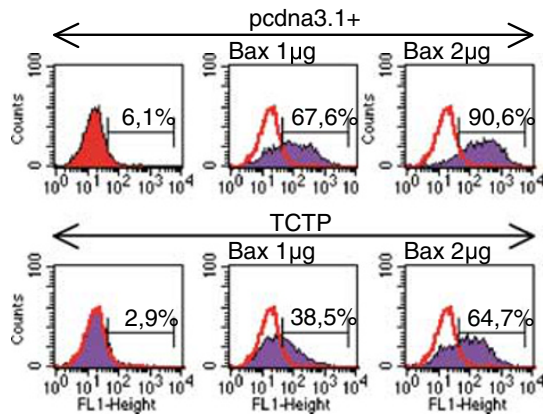

e pcdna $3.1++++\quad-\quad-\quad-$

Flag-TCTP - $\quad-\quad+++$

HA-Bax $\quad 0 \mu \mathrm{g} 1 \mu \mathrm{g} 2 \mu \mathrm{g} \quad 0 \mu \mathrm{g} 1 \mu \mathrm{g} 2 \mu \mathrm{g}$

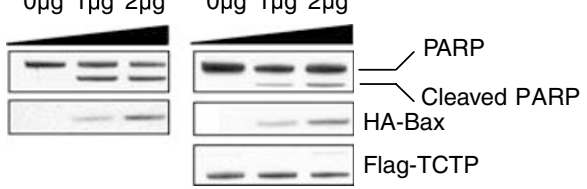

f

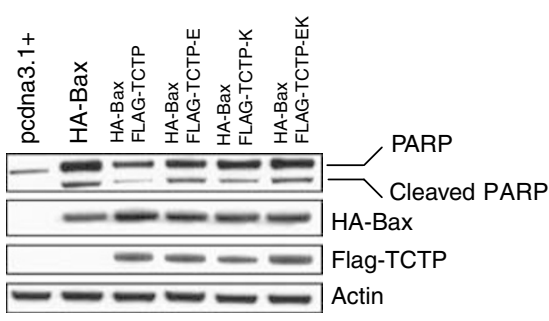

Figure 3 Mutations in helices H2-H3 of human TCTP decrease its antiapoptotic activity against staurosporine- or Bax-induced apoptosis. (a) TUNEL analysis of 293T cells incubated with staurosporine alone, with staurosporine and TCTP or with staurosporine and TCTP mutants. TCTP-EK denotes the double mutation of E109 and K102 to alanine. (b) Western blot analysis of PARP cleavage in 293T cells following staurosporine- or Bax-induced apoptosis in the presence and absence of TCTP. (c) Western blot analysis of PARP cleavage in 293T cells following staurosporine-induced apoptosis in the presence and absence of TCTP or TCTP mutants. TCTP-E denotes the E109A mutation; TCTP-K denotes the K102A mutation; TCTP-EK denotes the double mutation of E109 and K102 to alanine. (d) TUNEL analysis of 293T cells incubated with Bax alone or with Bax and TCTP. (e) Western blot analysis of PARP cleavage in 293T cells following Bax-induced apoptosis in the presence and absence of TCTP. (f) Western blot analysis of PARP cleavage in 293T cells following Bax-induced apoptosis in the presence and absence of TCTP or TCTP mutants. (Same mutants of TCTP as described in c)

We then investigated the effects of mutations of residues (E109 and K102) close to the turn between the two helices $\mathrm{H} 2$ and $\mathrm{H} 3$ of TCTP (Figure 4). A mutation of the hairpin residue
E109 to alanine alters slightly the effect of TCTP on staurosporine-induced apoptosis, while a mutation of $\mathrm{K} 102$ to alanine significantly diminishes the effect (Figure $3 a$ and c). 


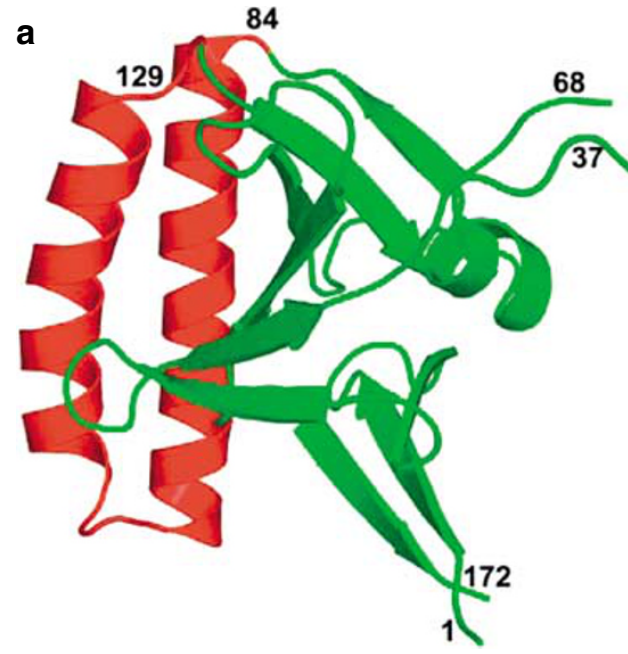

b

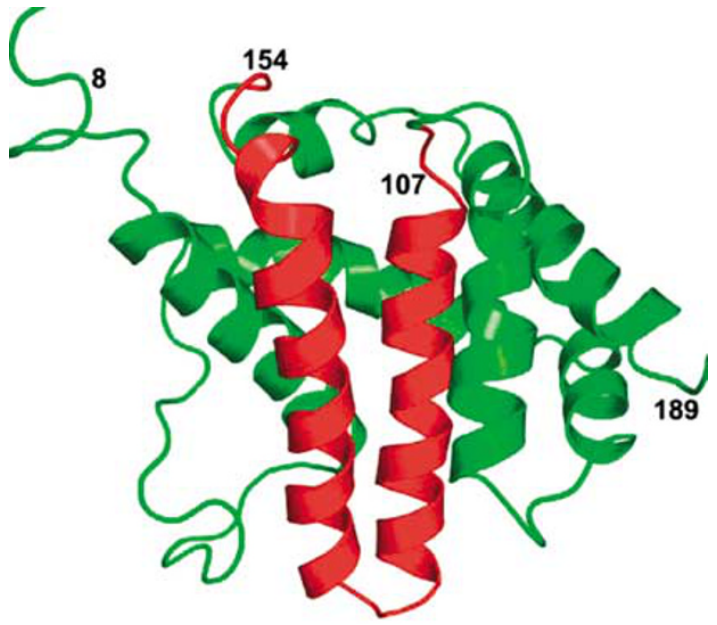

C

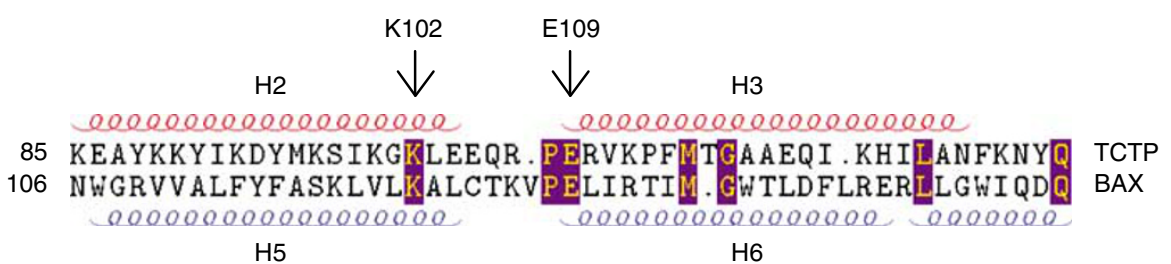

Figure 4 The three-dimensional structures of (a) human TCTP and (b) the pro-apoptotic protein Bax (PDB code: 1F16). The $\alpha$-helical hairpin (shown in red) common to the two structures is displayed here in a similar orientation. (c) Alignment of the two helical hairpin residues of TCTP $(\mathrm{H} 2, \mathrm{H} 3)$ and BAX (H5, H6). The position of the mutated residues is indicated (conserved residues are highlighted in pink)

The effect of the double mutation of $\mathrm{E} 109$ and $\mathrm{K} 102$ is identical to the effect of the K102A mutation alone. Both single mutants and the double mutant diminish the antiapoptotic effect of TCTP on Bax-induced apoptosis (Figure $3 f)$. Since the helices $\mathrm{H} 2-\mathrm{H} 3$ of TCTP appear to play a role in the protein's antiapoptotic activity, we wished to investigate the effect of replacing helices $\mathrm{H} 5-\mathrm{H} 6$ of Bax by helices $\mathrm{H} 2-\mathrm{H} 3$ of TCTP on the induction of apoptosis. The chimeric protein, BTB (Bax/ TCTP H2-H3/Bax), expressed in 293T cells has a strong pro-apoptotic function, comparable to that of wild-type Bax as assessed both by levels of TUNEL-positive cells (Supplementary Figure 1a) and the extent of PARP cleavage (Supplementary Figure 1b). The double mutation in BTB of both residues (K126 the residue corresponding to K102 in TCTP and E133 the residue corresponding to E109 in TCTP) to alanine resulted in a significant reduction in pro-apoptotic strength.

The antiapoptotic function of TCTP occurs at the mitochondria where it inhibits Bax-induced damage. To establish whether or not the antiapoptotic activity of TCTP takes place at the level of the mitochondria in the above experiments, we used an acellular system of purified mitochondria. ${ }^{28}$ The purified mitochondria were directly incubated (Figure 5a) with the in vitro translation (IVT) products of the proteins. The insert in Figure $5 \mathrm{a}$ shows the expression of the proteins added. In these assays (Figure 5a, Supplementary Figure 2), TCTP inhibits mitochondrial damage induced by Bax, while the double mutant of TCTP in which both E109 and K102 are replaced by alanine is much less efficient in inhibiting Bax-induced damage. These results agree well with those obtained by monitoring levels of TUNEL-positive cells and the extent of PARP cleavage and suggest that the antiapoptotic function of TCTP takes place, at least in part, in the mitochondria, with TCTP inhibiting the function of Bax.

TCTP anchors into the mitochondria and inhibits the dimerization of Bax. We further tried to identify how TCTP would 'neutralize' the apoptotic effect of Bax. We first investigated whether wild-type or mutant TCTP binds directly or indirectly Bax. Neither a GST-IVT pull down nor a coimmunoprecipitation of endogenous or overexpressed Bax and TCTP yielded any positive results (data not shown), in agreement with previous reports suggesting that there was no direct interaction between TCTP and Bax. ${ }^{4,7}$ To further evaluate the potential role of TCTP at the level of the mitochondria, we assessed the anchorage of TCTP into the mitochondrial membranes. For that purpose, freshly isolated mitochondria were incubated in the presence of recombinant TCTP and treated with $\mathrm{Na}_{2} \mathrm{CO}_{3}$, which eliminates loosely bound proteins and spares proteins that are anchored into the membranes. Figure $5 b$ shows that approximately $0.25 \mathrm{pmol}$ TCTP or TCTP-EK (lanes 2, 3) do anchor into $125 \mu \mathrm{g}$ of mitochondria. This amount represents less than $1 \%$ of the total amount of recombinant TCTP that was allowed to incubate in the presence of the mitochondria. $0.5-20 \mathrm{pmol}$ TCTP were also loaded on the same western blot to allow a 
a

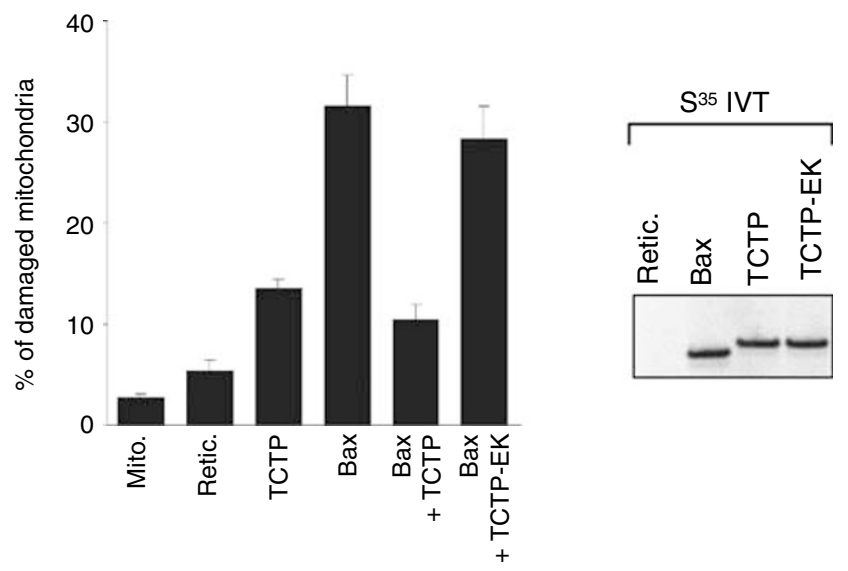

b
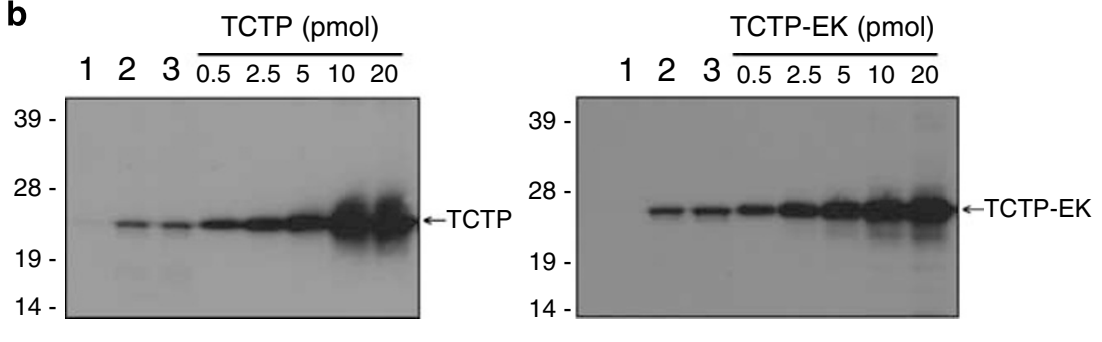

c

$14-$

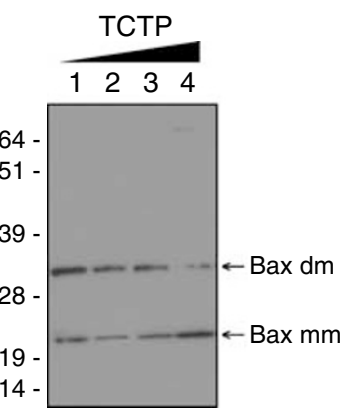

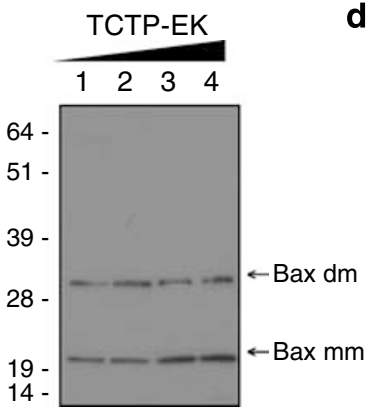

d

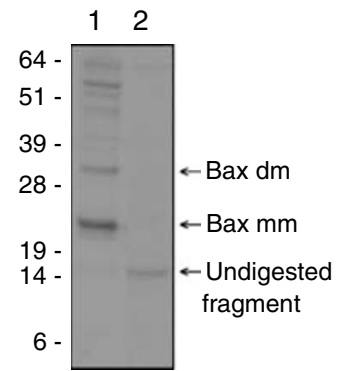

Figure 5 TCTP protects the mitochondria against Bax. (a) Analysis of the integrity of the outer mitochondrial membrane (rat liver). The cellular fraction of purified mitochondria was placed in the presence of the in vitro translation (IVT) products of TCTP, Bax, Bax and TCTP or Bax and TCTP-EK. Mitochondria alone (Mito). Retic. lysate alone (Retic). The oxidation of cytochrome $c$ was used as a marker of mitochondrial damage. Inset: SDS-PAGE showing IVTs. (b) Anchorage of TCTP into the mitochondria. Western blot analysis of TCTP (left panel) and TCTP-EK (right panel) anchorage onto the mitochondria. Lane 1: mitochondria (125 $\mu \mathrm{g}$ ), lanes 2 and 3 mitochondria (125 $\mu \mathrm{g}$ ) incubated in the presence of $100 \mathrm{pmol}$ TCTP (left panel) or TCTP-EK (right panel), washed and treated with $\mathrm{Na}_{2} \mathrm{CO}_{3}$. Increasing amounts of TCTP (left panel) or TCTP-EK (right panel) were loaded to evaluate quantitatively the anchorage. (c) Bax dimerization. Western blot analysis of Bax anchorage into the mitochondria after treatment by increasing amounts of TCTP (left panel) or TCTP-EK (right panel). Lane 1: no treatment, lanes 2, 3 and 4 respectively treated with 5, 10 and $20 \mathrm{nM}$ of TCTP (left panel) or TCTP EK (right panel). Arrows indicate Bax monomer (Bax mm) or Bax dimer (Bax dm). (d) Trypsin digestion assay. Western blot analysis of Bax anchorage into the mitochondria without (lane 1) or after trypsin digestion (lane 2)

quantitative comparison. No difference between TCTP and TCTP-EK could be detected with regard to their anchorage capacity into the mitochondria. The anchorage of proteins into the mitochondrial membrane is a well regulated process. ${ }^{29}$ As documented in Supplementary Figure 3, Bax anchors into the mitochondrial membrane only when activated by tBid. tBid binds loosely, is sensitive to alkali treatment and thus is not anchored into the mitochondrial membrane. ${ }^{29}$

We then analyzed whether the anchorage of TCTP could interfere with the pro-apoptotic function of Bax. Figure $5 \mathrm{c}$ (left panel) indicates that increasing amounts of TCTP do not inhibit the anchorage of Bax monomers but do inhibit the dimeric form of anchored Bax. On the other hand, TCTP-EK (Figure 5c right panel) does not inhibit the formation of this dimeric form indicating that intact helices of TCTP are necessary to interfere with the dimerization process of Bax when already anchored into the mitochondrial membranes. tBid and TCTP (or TCTP-EK) alone do not generate any Bax signal (data not shown). To consolidate the fact that the $30-35 \mathrm{kDa}$ band, recognized by the polyclonal rabbit anti-Bax antibodies, corresponds to a dimeric form of Bax, we performed a trypsin digestion assay. Trypsin digestion is highly efficient on a wide variety of proteins among which is the monomeric form of Bax. In contrast, the dimeric form of Bax is resistant to complete digestion by trypsin, sparing a fragment of $15 \mathrm{kDa}$ that is recognized 
by this antibody which was directed against a synthetic peptide corresponding to amino acids 43-61 of human Bax (Figure 5d lane 2) (Lucken-Ardjomande S, Montessuit S, and Martinou JC. Cell Death Differ (in press)). Monoclonal antiBax antibodies directed against amino acids 3-16 of Bax do not recognize this $15 \mathrm{kDa}$ undigested peptide, since this region has been digested by trypsin (data not shown). Together, these results suggest that the 30-35 kDa band corresponds to Bax dimers. Nevertheless this assay does not allow discrimination between a homo- or heterodimeric form of Bax.

\section{Discussion}

Since the discovery of TCTP by Yenofsky, it became clear that this protein is implicated in multiple biological processes (Figure 6a) such as cell growth, division, proliferation, and inhibition of programmed cell death. ${ }^{2-14,16}$ It also functions as a histamine releasing factor ${ }^{15}$ and is secreted through the non-classical exosome pathway interacting with TSAP6, a p53-regulated gene. ${ }^{30,31}$ It seems that all these different functions of TCTP are related to specific association with various protein partners. The cell growth regulatory function of TCTP is related to its guanine nucleotide dissociation inhibitor activity for the elongation factors $\mathrm{EF} 1 \mathrm{~A}$ and $\mathrm{EF} 1 \mathrm{~B} \beta .^{32} \mathrm{We}$ previously suggested that by inhibiting the dissociation of GDP from these two components of the translational machinery, TCTP would slow down the elongation process, this way avoiding 'skipping' and finally rendering elongation more efficient. A second observation implicating TCTP in cell growth, was recently made through the study of Drosophila TCTP genetics. ${ }^{12}$ This study shows that TCTP would regulate the TSC1 and TSC2 pathway where it would function as a GEF-like protein for Rheb. Being upstream of the mTOR pathway, would place TCTP in a strategic position for regulating cell growth. It is however difficult to reconcile these Drosophila results with the yeast, where TSC1 and TSC2 do not exist and where Rheb does not appear to function in mTOR pathway; despite highly elevated levels of TCTP. It is interesting to note that TCTP would be implicated in the processes cell growth, proliferation and survival since this relates so closely to the TSC1, TSC2, mTOR pathway. Regardless of the mechanism involved, the data presented herein confirm an important contribution of TCTP in the control of cell growth and proliferation. Embryos lacking tctp fail to grow and mutant cells to proliferate.

The crystal structure of human TCTP is highly similar to that of TCTP from $S$. pombe, confirming the common fold

a

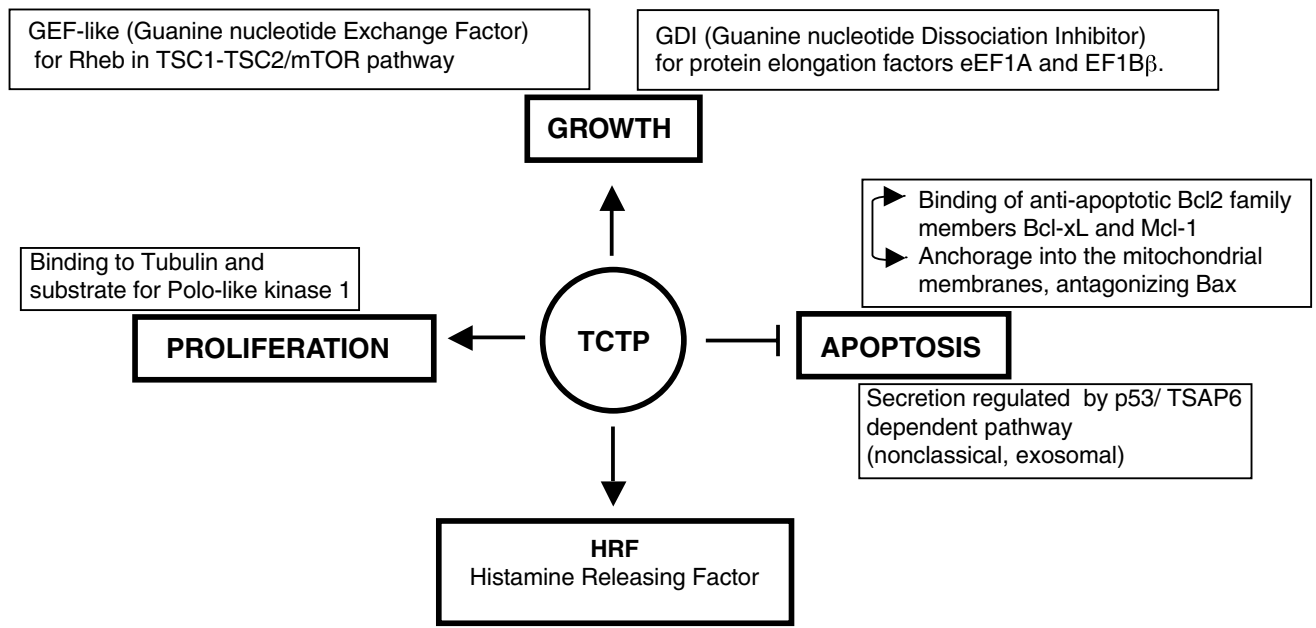

b

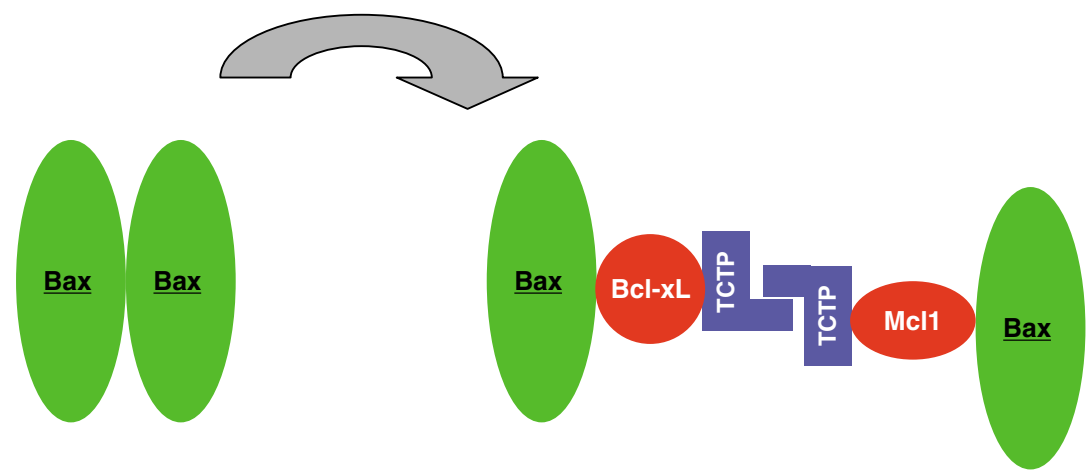

Figure 6 (a) The different functions of TCTP and their potential mechanism of action. (b) Schematic representation of the potential antiapoptotic mechanism of TCTP 
expected from the sequence homology. ${ }^{20}$ As noted previously, TCTP shows structural homology to Mss4, a protein originally described as guanine nucleotide exchange factor for Rab proteins but later identified as a guanine nucleotide-free chaperone. ${ }^{33}$ Mss4, however, lacks helices H2-H3, contains a zinc-binding site absent in TCTP and differs in the topological placement of a small $\beta$-sheet and a long mobile loop. $^{20}$ Despite a common core fold, these structural differences and the lack of any clear evidence for functional similarities weaken the suggestion that TCTP and Mss4 families of proteins are related. Similarly, the structural homology with $\mathrm{MsrB}^{22}$ does not seem to extend to any common function, since the catalytic residues of MsrB are absent in TCTP.

Structural analysis of TCTP and members of the Bcl2 family yields some insight into possible mechanisms for the control of apoptotic processes. The structure of $\mathrm{Bcl}-\mathrm{xL}^{25}$ revealed a similarity between its $\mathrm{H} 5-\mathrm{H} 6$ and the channel-forming domains of diphtheria toxin and bacterial colicins $A$ and $\mathrm{E} 1{ }^{23}$ With the determination of a number of structures of proteins from the $\mathrm{Bcl} 2$ family, $^{17}$ it has become clear that pro- and antiapoptotic members of the family have similar folds with the central core helices $\mathrm{H} 5-\mathrm{H} 6$ flanked by the other $\alpha$-helices and function as regulators of the mitochondrial membrane permeability where they would influence the opening of specialized pores. ${ }^{17,24-27}$ It is presumed today that the balance between the pro-apoptotic and the antiapoptotic will define the level of permeability of those pores rather than the helices creating the pores. The crystal structure of TCTP reveals a similar pair of helices and we have sought here to characterize the role of these helices in the antiapoptotic function of the protein.

It has been inferred that TCTP is antiapoptotic since decreasing its protein levels leads to apoptosis or reversion of malignant phenotypes. ${ }^{2-7}$ Importantly, TCTP has been shown to bind to $\mathrm{MCL} 1^{2,4,7}$ and $\mathrm{BCl}-\mathrm{xL},{ }^{6}$ both antiapoptotic members of the Bcl2 family. TCTP is therefore closely associated with apoptotic processes. We show here that loss of tctp expression results in a dramatic increase in apoptotic cell death during embryogenesis. This phenotype, together with the proliferation defect observed in these mutants, is sufficient to explain why the tctp-null mice die early during embryogenesis. Of note, another tctp-mouse model has recently been generated and the data reported ${ }^{34}$ are in keeping with these observations. Together, these genetic data clearly highlight a critical role for tctp in the control of cell survival in vivo. Moreover, mutagenesis of residues in helices $\mathrm{H} 2-\mathrm{H} 3$ of TCTP reduces its antiapoptotic function. The creation of a chimeric protein, BTB, in which the helices $\mathrm{H} 2-\mathrm{H} 3$ of TCTP replace helices $\mathrm{H} 5-\mathrm{H} 6$ of Bax, does not disrupt the pro-apoptotic function of this $\mathrm{Bcl} 2$ family protein. Mutations in BTB corresponding to those made in TCTP do however disrupt this activity. Together these results show that the pair of helices function equally well in the context of a pro- or antiapoptotic protein, and that mutations diminish this activity. It may therefore be that the precise molecular event in which the pair of helices participates is similar in the context of TCTP or BTB. Sequence homology for these helices is low even between members of the Bcl2 family, although the helices are structurally and functionally conserved. ${ }^{17,24-27}$ As a result, the helices are excluded from the definition of the Bcl2 homology domain, ${ }^{1}$ yet the similarity found here suggests a structural feature common to a set of proteins involved in apoptotic processes.

Previous immunofluorescence data suggested that TCTP colocalizes with $\mathrm{Bcl}-\mathrm{xL}$ and $\mathrm{MCL} 1$ and therefore acts at the mitochondria, similarly to other key regulators of apoptosis. However, the high abundance of TCTP in the cytoplasm renders interpretation of those data rather complicated. For this reason we used a purified fraction of mitochondria to perform our experiments. Our data indicate that TCTP antagonizes the function of Bax and requires its pair of helices to participate in antiapoptotic activity at the level of the mitochondria. Nevertheless, it is clear that those $\mathrm{H} 2-\mathrm{H} 3$ helices are not per se required for the binding and anchorage of the protein into the mitochondria as revealed by the mutant TCTP-EK, which binds and anchors as efficiently as wild-type TCTP to the mitochondria. There are at least two possible interpretations to explain this weakening of mutant TCTP. It is possible that while the amount of TCTP and TCTP-EK protein binding and anchoring in the mitochondria remain similar, the conformation of the protein in the membrane and its binding to MCL1 and Bcl-xL would be affected. It is also possible that the mutation of these helices would impair to some extent the dimerization of TCTP.

The 'rheostat' model suggests that the balance between pro- and antiapoptotic members of the $\mathrm{Bcl} 2$ family determines the fate of a cell. However, this model is not sufficient to explain our results because TCTP does not bind directly to Bax (Liu et al., 2005 ${ }^{4}$; Zhang et al., 2002 ; our results). We therefore propose that TCTP would bind antiapoptotic members of the Bcl2 family, as described for $\mathrm{MCL} 1^{2,4,7}$ and $\mathrm{Bcl}-\mathrm{xL},{ }^{6}$ and possibly arrange them in such a way into the mitochondrial membranes that their antiapoptotic action would be more efficient. We suggest that this is the 'enhancer' part of the model that would regulate the efficiency of the 'rheostat'. Furthermore, we suggest that TCTP would anchor into the mitochondrial membrane and inhibit the formation of dimeric Bax. One possible interpretation of this would be that TCTP, following its anchorage into the membrane, would separate and distance Bax homodimers (Figure 6b), but this necessitates further investigation.

\section{Materials and Methods}

Generation of tctp knockout mice and genotyping. Genomic DNA was prepared from 129/Svj ES cells using established procedures. PCR was performed using expand long template (Roche, France) in buffer 1 following the manufacturer's recommendations.

Three fragments $(a, b$ and $c$ ) overlapping $8,8 \mathrm{~kb}$ of the genomic region containing the murine tctp gene on chromosome 14 were amplified using following primers:

F(a) 5'-GATGCGGCCGCCTGTCCATTAGAGTACCGG-3',

R(a) 5'-CTCGATATCCCTGAAACATCTTAACCTACC-3',

F(b) 5'-AGGGATATCGAGCTGACTGATCGTTGCCGG-3'

R(b) $5^{\prime}$-TTCGGATCCCACAGTTATTATACAACCCTT-3'

F(c) $5^{\prime}$-GTGGGATCCGAAAAAGTCTGTTTGCTGTCT-3'

R(c) 5'-CTCGTCGACGGGGGCGTTGCTCACTGAGAG-3'

These 3 amplicons were cloned in a pBluescript (pBS) vector digested with Notl/ Sall. One 46 bp oligonucleotide containing a LoxP site floxed by 2 EcoRV sites and one neomycin resistance gene with one LoxP site at each end were cloned respectively in $5^{\prime}$ of exon 3 and in $3^{\prime}$ of exon 5 . This construct was linearized and injected into C57BI6 ES cells to obtain recombinant mice in which the exons 3, 4 and 5 were excised upon Cre-mediated recombination. 
Genotyping was performed on genomic DNA from mouse tails or yolk sacs. A PCR-based strategy was developed to distinguish between the wild-type and tctp mutant alleles. The primers are as follows (see Figure 1a):

F1 5'-GAGTGACCACCTCTCTCAGTCC- ${ }^{\prime}$

R1 $5^{\prime}$-AACACCGGTGACTACTGTGCTTTCG-3'

F2 $5^{\prime}$-GGGAGTGCAGCAGTGATTCTTTGCC- $3^{\prime}$

R2 $5^{\prime}$-AAGGCACTGTCTCCACCAGTCCC-3'

When primers $F 1, R 1$ and $R 2$ are used in the same reaction (see Figure 1c), a $423 \mathrm{bp}$ fragment indicates the presence of the mutated allele $\left(\operatorname{tctp}^{\Delta 3-5}\right)$, whereas $300 \mathrm{bp}$ fragment is amplified from the wild-type allele (see Figure 1b).

Mouse embryo fibroblasts were prepared from 12.5-days-old embryos using established procedures. Cells and organs were lysed in hypertonic buffer $(50 \mathrm{mM}$ Tris- $\mathrm{HCl} \mathrm{pH} \mathrm{7.5,} 250 \mathrm{mM} \mathrm{NaCl}, 10 \mathrm{mM}$ EDTA, $1 \mathrm{mM}$ DTT and 1\% NP40).

Histology. For sectioning, embryos were fixed in $4 \%$ paraformaldehyde $1 \times$ PBS overnight, paraffin embedded, sectioned and stained in hematoxylin and eosin.

Immunohistochemistry and TUNEL assay. The following antisera were used: anticleaved caspase-3 (1/200, Cell Signaling); antiphosphorylated histone-H3 (PH3) (1/200, Upstate). Avidin-conjugated peroxidase (ABC and DAB kits from Vector Laboratories) was used for immunodetection. TUNEL assay was used to detect apoptotic cells on sections of paraffin-embedded embryos using the 'In Situ Death Detection Kit' (TmR red, Roche). After TUNEL staining, embryo sections were counterstained and mounted using Vectashield with DAPI (Vector H-1200).

Crystallization and data collection. Initial crystallization conditions were found by screening different precipitating agents. Different crystal forms were crystallized by the hanging drop vapor-diffusion method at $4^{\circ} \mathrm{C}$ using polyethylene glycol (PEG) $5000 \mathrm{MME}$ as the crystallization agent. Crystallization trials were set up using equal volumes of protein (concentrated to $3 \mathrm{mg} / \mathrm{ml}$ ) and reservoir. The best crystals were grown against a reservoir containing $25 \%$ PEG $5000 \mathrm{MME}, 50 \mathrm{mM}$ Bis Tris (Bis(2-hydroxyethyl) iminotris (hydroxymethyl) methane) buffer pH 6.2, $50 \mathrm{mM}$ magnesium acetate and 3\% 1,6-hexanediol. These crystals diffracted beyond $2.0 \AA$ resolution at the European Synchrotron Radiation Facility ID14-1 beam line, and belong to the monoclinic space group $P 2_{1}$, with unit-cell parameters $\mathrm{a}=63.8$, $b=93.7, c=70.4 \AA, B=114.9$. A complete data set was obtained from a single crystal cooled to $140 \mathrm{~K}$ from 150 frames of $1^{\circ}$ oscillation (wavelength of $0.934 \AA$, crystal-detector distance of $180 \mathrm{~mm}$ ) using an ADSC Q4R CCD detector. The estimated $V_{m}$ of $2.3 \AA^{3} / D a$ indicates four molecules of TCTP in the asymmetric unit and corresponds to a solvent content of $47 \%$, assuming a protein density of $1.22 \mathrm{~g} / \mathrm{cm}^{3}$. Data were processed with the package HKL2000. ${ }^{35}$

Structure determination. The structure of human TCTP was solved by the molecular replacement method (Program MOLREP, AMoRe supplemented in $\mathrm{CCP}^{36}$ ) using the NMR coordinates of $S$. pombe TCTP (PDB code: $1 \mathrm{H} 7 \mathrm{Y}$ ). The refined model contains four human TCTP molecules of 155 residues (residues 39-66 are not visible in the final electron density map) and 508 water molecules. The crystallographic R-factor is $19.1 \%$ using all reflections between 25 and $2.0 \AA$ with no sigma cutoff $\left(R_{\text {free }}=23.8 \%\right.$, using a random sample containing $7.5 \%$ of the data). The models were refined with the CNS program, ${ }^{37}$ using the Engh and Huber stereochemical parameter set. All rebuilding and graphics operations were done with $\mathrm{O}$ and related Uppsala programs. ${ }^{38}$ All crystallographic calculations were carried out with the CCP4 package. ${ }^{36}$ The stereochemistry of the model was inspected using Procheck ${ }^{39}$ and the quality of the refined structure was assessed using the Biotech validation suite for protein structures. ${ }^{40}$ In each monomer, $92.9 \%$ of the residues are in the most favored regions of the Ramachandran plot $(7.1 \%$ in additional allowed regions). Data collection statistics and refinement statistics are presented in Supplementary Table 2.

Coordinates of human TCTP at $2.0 \AA$ resolution have been deposited in the Protein Data Bank (accession code: 1YZ1).

Figures were prepared with PyMOL (Delano Scientific, http://www.pymol.org) and TeXshade.

Expression constructs and mutagenesis. The coding regions of human Bax- $\alpha$ and human TCTP were cloned into the EcoRI and Xhol sites of the plasmid vector PCDNA3.1. (Invitrogen), with a HA tag and a Flag tag respectively. BTB was obtained by replacing $\mathrm{Bax} \mathrm{H} 5$ and $\mathrm{H} 6$ helices by TCTP $\mathrm{H} 2$ and $\mathrm{H} 3$ helices.
BTB sequence:

MDGSGEQPRGGGPTSSEQIMKTGALLLQGFIQDRAGRMGGEAPELALDPVP QDASTKKLS

ECLKRIGDELDSNMELQRMIAAVDTDSPREVFFRVAADMFSDGNFNTGKEAY KKYIKDYM

KSIKGKLEEQRPERVKPFMTGAAEQIKHILRTGWIQDQGGWDGLLSYFGTPT WQTVTIFV

AGVLTASLTIWKKMG*

This BTB sequence corresponds to the following construction: $\mathrm{BAX}_{1-106}, \mathrm{TG}$, TCTP $_{85-126}, R T, B_{150-192}$. The TCTP insert has been underlined in the BTB sequence above.

TCTP mutants TCTP-E109A, TCTP-K102A, TCTP-EK and BTB mutants BTB-E133A, BTB-EK were obtained using QuickChange site-directed mutagenesis (Stratagene) following the manufacturer's protocol. All mutants were confirmed by automated DNA sequencing.

Purification of recombinant protein. Full-length TCTP CDNA was cloned in-frame in the pGEX-6P vector (GE Health Care). Expression of the GST-fusion protein in BL21 (DE3) bacteria strain (Stratagene) was induced by the addition of $0.1 \mathrm{mM} \mathrm{IPTG}$ for $16 \mathrm{~h}$ at room temperature. Cells were lysed for $30 \mathrm{~min}$ in a $1 \%$ Nonidet P-40 buffer (10 mM Tris- $\mathrm{HCl}, \mathrm{pH} 7.5,150 \mathrm{mM} \mathrm{NaCl}, 10 \%$ glycerol, $1 \mathrm{mM}$ EDTA, plus the protease inhibitors $1 \mathrm{mM} \mathrm{AEBSF}, 1 \%$ aprotinin, $1 \mathrm{mM}$ leupeptin, and $2 \mathrm{mM}$ pepstatin (all reagents from ICN)). The lysates were clarified by sonication and centrifugation $(16000 \times \mathrm{g})$ for $30 \mathrm{~min}$ at $4{ }^{\circ} \mathrm{C}$, and the GST-fusion protein was purified with glutathione-sepharose beads (GE Health Care). The beads were washed three times with the $1 \%$ Nonidet P-40 buffer and TCTP protein was cleaved from GST tag by Prescission protease (GE Health Care). The quality of the purified protein was assessed by SDS-PAGE and Coomassie blue staining. The purified protein was dialyzed and stored at $4^{\circ} \mathrm{C}$ in $50 \mathrm{mM} \mathrm{Hepes} \mathrm{pH} 7$ and $100 \mathrm{mM} \mathrm{NaCl}$.

Cell culture. 293T cells were maintained in DMEM containing 10\% (v/v) FBS and $1 \%(\mathrm{v} / \mathrm{V})$ penicillin-streptomycin-glutamine. 293T cells were transiently transfected by the calcium phosphate method. In all experiments, carrier DNA was added to maintain equal plasmid concentrations between different samples.

Antibodies. Rabbit anti-TCTP antibodies were generated against the human protein TCTP. The corresponding polyclonal antiserum was affinity-purified on a column coupled with the protein (Agro-Bio). This antibody is used at a 1/4000 dilution in western blot analysis. Goat anti-Actin 119 antibody (Santa Cruz Biotechnology) or mouse monoclonal anti- $\gamma$-tubulin (SIGMA) was used at $1 / 1000$ for equal loading. Secondary antibodies, antigoat, antirat, antirabbit or antimouse HRP-linked (Calbiochem) were used at a 1/5000 dilution. Anti-cytochrome $c(6 \mathrm{H} 2)$ and anti-Smac (V17) (Santa Cruz Biotechnology), anti-HA (Babco), anti-Flag (M2, Sigma), anti-PARP (C2.10, ICN), anti-MTCO1 (ab14705, abcam), anti-Bax (Pharmingen).

Flow cytometry. The TUNEL assay was performed using an In Situ Cell Death detection kit (Roche Applied Science) according to the manufacturer's instructions and cells were analyzed in a FACScan cell sorter (Becton Dickinson).

\section{Binding of TCTP to the mitochondria and cytochrome $c$ oxydase} assay. Mitochondria were isolated ${ }^{28}$ from normal rat liver using a mitochondria isolation kit (Sigma Aldrich). For mitochondrial targeting assays, $\left[{ }^{35} \mathrm{~S}\right]$ Met-labeled proteins (GE Health Care) were synthesized from CDNAs using the TNT-coupled Transcription/Translation system (Promega, France). Radio-labeled Bax, TCTP, TCTP-EK, were incubated with isolated mitochondria $(2.5 \mathrm{mg}$ proteins $/ \mathrm{ml})$ at $30^{\circ} \mathrm{C}$ for $1 \mathrm{~h}$ in $40 \mu \mathrm{l}$ of standard import buffer $(250 \mathrm{mM}$ sucrose, $80 \mathrm{mM} \mathrm{KCl}, 10 \mathrm{mM}$ $\mathrm{MgCl}_{2}, 10 \mathrm{mM}$ malic acid, $8 \mathrm{mM}$ succinic acid, $1 \mathrm{mM} \mathrm{ATP}-\mathrm{Mg}^{2+}, 20 \mathrm{mM}$ MOPS, $\mathrm{pH}$ 7.5). Where indicated, ${ }^{35} \mathrm{~S}$-Bax was pre-incubated with radiolabeled TCTP or TCTP-EK for $30 \mathrm{~min}$ prior to incubation with mitochondria. The integrity of the outer membrane was assessed by measuring cytochrome $c$ oxidase activity in mitochondrial membranes in the presence and absence of a detergent, $n$-dodecyl-D-maltoside, one of few detergents that allows the cytochrome $c$ oxidase dimer to be maintained in solution at low detergent concentrations. The ratio between activity in the presence and absence of the detergent is a measure of the integrity of the mitochondrial outer membrane. The assay was performed using a cytochrome $c$ oxidase assay kit (Sigma), according to the manufacturer's instructions. Alternatively, cytochrome $c$ was detected in the supernatant of the mitochondria by western blot analysis using anti-cytochrome $c$ antibodies. 
Anchorage assay of TCTP into the mitochondrial membrane. Mitochondria were purified from rat liver by differential centrifugation. $125 \mu \mathrm{g}$ of freshly prepared mitochondria were incubated in the presence of 5-20 nM recombinant TCTP or TCTP-EK at $30^{\circ} \mathrm{C}$ for $10 \mathrm{~min}$. Samples were washed and treated with $\mathrm{Na}_{2} \mathrm{CO}_{3}$ followed by centrifugation at $100000 \times \mathrm{g}$ for $1 \mathrm{~h}^{29}$

Bax dimerization assay. Mitochondria preparation and incubation with TCTP $(20 \mathrm{nM})$ or TCTP-EK $(20 \mathrm{nM})$ were performed as above. Hereafter, recombinant tBid $(5 \mathrm{nM})$ was added for $5 \mathrm{~min}$ at $30^{\circ} \mathrm{C}$, followed by an incubation with recombinant $\mathrm{Bax}(10 \mathrm{nM})$ for $7 \mathrm{~min}$ at $30^{\circ} \mathrm{C} . \mathrm{Na}_{2} \mathrm{CO}_{3}$ treatment was performed as above followed by western blot analysis.

Trypsin digestion assay. $250 \mu \mathrm{g}$ of freshly prepared mitochondria were incubated in the presence of Bax (100 nM) and tBid $(10 \mathrm{nM})$ for $10 \mathrm{~min}$ at $30^{\circ} \mathrm{C}$ and treated with $\mathrm{Na}_{2} \mathrm{CO}_{3}$ as above. Samples were resuspended in $50 \mu \mathrm{KCl}$ buffer and $10 \mu \mathrm{g}$ of trypsin was added. Digestion occurred for $2 \mathrm{~h}$ at $30^{\circ} \mathrm{C}$ and analyzed by western blot using the polyclonal rabbit antibody directed against the amino acids 43-61 of human Bax (Pharmingen) (Lucken-Ardjomande S, Montessuit S, and Martinou JC. Cell Death Differ (in press)). This antibody detects the undigested $15 \mathrm{kDa}$ fragment of Bax dimers.

Acknowledgements. This study is part of the $\mathrm{PhD}$ thesis of Dominique Duflaut (Université Paris XI) and Alexandra Lespagnol (Université Paris VII). We thank the staff of the European Synchrotron Radiation Facility beam line ID14-1 for use of their synchrotron instrumentation and help during data collection. We are in debt to Pierre Chambon for his longstanding support and grateful to Tania Sorg and Daniel Metzger for their help and advice in the generation of the tctp knockout mice. $\mathrm{CB}$ is supported by a grant from the Belgian Foundation for Cancer Research.

\section{Competing interest statement}

The authors declare that they have no competing financial interests.

1. Danial NN, Korsmeyer SJ. Cell death: critical control points. Cell 2004; 116: 205-219.

2. Graidist $P$, Phongdara A, Fujise K. Antiapoptotic protein partners fortilin and MCL1 independently protect cells from 5-fluorouracil-induced cytotoxicity. J Biol Chem 2004; 279: 40868-40875.

3. Li F, Zhang D, Fujise K. Characterization of fortilin, a novel antiapoptotic protein. J Biol Chem 2001; 276: 47542-47549.

4. Liu H, Peng HW, Cheng YS, Yuan HS, Yang-Yen HF. Stabilization and enhancement of the antiapoptotic activity of mcl-1 by TCTP. Mol Cell Biol 2005; 25: 3117-3126.

5. Tuynder M, Susini L, Prieur S, Besse S, Fiucci G, Amson R et al. Biological models and genes of tumor reversion: cellular reprogramming through tpt1/TCTP and SIAH-1. Proc Natl Acad Sci USA 2002; 99: 14976-14981.

6. Yang $Y$, Yang $F$, Xiong Z, Yan $Y$, Wang $X$, Nishino $M$ et al. An N-terminal region of translationally controlled tumor protein is required for its antiapoptotic activity. Oncogene 2005; 24: 4778-4788.

7. Zhang D, Li F, Weidner D, Mnjoyan ZH, Fujise K. Physical and functional interaction between myeloid cell leukemia 1 protein (MCL1) and Fortilin. The potential role of MCL1 as a fortilin chaperone. J Biol Chem 2002; 277: 37430-37438.

8. Chitpatima ST, Makrides S, Bandyopadhyay R, Brawerman G. Nucleotide sequence of a major messenger RNA for a 21 kilodalton polypeptide that is under translational control in mouse tumor cells. Nucleic Acids Res 1988; 16: 2350

9. Bommer UA, Lazaris-Karatzas A, De Benedetti A, Nurnberg P, Benndorf R, Bielka $\mathrm{H}$ et al. Translational regulation of the mammalian growth-related protein P23: involvement of elF-4E. Cell Mol Biol Res 1994; 40: 633-641.

10. Yenofsky R, Cereghini S, Krowczynska A, Brawerman G. Regulation of mRNA utilization in mouse erythroleukemia cells induced to differentiate by exposure to dimethyl sulfoxide. Mol Cell Biol 1983; 3: 1197-1203.

11. Norbeck J, Blomberg A. Two-dimensional electrophoretic separation of yeast proteins using a non-linear wide range $(\mathrm{pH} 3-10)$ immobilized $\mathrm{pH}$ gradient in the first dimension; reproducibility and evidence for isoelectric focusing of alkaline $(\mathrm{pl}>7)$ proteins. Yeast 1997; 13: 1519-1534.

12. Hsu YC, Chern JJ, Cai Y, Liu M, Choi KW. Drosophila TCTP is essential for growth and proliferation through regulation of dRheb GTPase. Nature 2007; 445: 785-788.

13. Gachet $Y$, Tournier S, Lee M, Lazaris-Karatzas A, Poulton T, Bommer UA. The growthrelated, translationally controlled protein $\mathrm{P} 23$ has properties of a tubulin binding protein and associates transiently with microtubules during the cell cycle. J Cell Sci 1999; 112 (Part 8): 1257-1271.

14. Yarm FR. Plk phosphorylation regulates the microtubule-stabilizing protein TCTP. Mol Cell Biol 2002; 22: 6209-6221.

15. MacDonald SM, Rafnar T, Langdon J, Lichtenstein LM. Molecular identification of an IgEdependent histamine-releasing factor. Science 1995; 269: 688-690.

16. Tuynder M, Fiucci G, Prieur S, Lespagnol A, Geant A, Beaucourt S et al. Translationally controlled tumor protein is a target of tumor reversion. Proc Natl Acad Sci USA 2004; 101 15364-15369.

17. Petros AM, Olejniczak ET, Fesik SW. Structural biology of the Bcl-2 family of proteins. Biochim Biophys Acta 2004; 1644: 83-94.

18. Suzuki M, Youle RJ, Tjandra N. Structure of Bax: coregulation of dimer formation and intracellular localization. Cell 2000; 103: 645-654.

19. Fiucci $G$, Lespagnol A, Stumptner-Cuvelette $P$, Beaucourt S, Duflaut D, Susini $L$ et al. Genomic organization and expression of mouse Tpt1 gene. Genomics 2003; 81: 570-578.

20. Thaw P, Baxter NJ, Hounslow AM, Price C, Waltho JP, Craven CJ. Structure of TCTP reveals unexpected relationship with guanine nucleotide-free chaperones. Nat Struct Biol 2001; 8: 701-704

21. Baxter NJ, Thaw P, Higgins LD, Sedelnikova SE, Bramley AL, Price $C$ et al. Backbone NMR assignment of the $19 \mathrm{kDa}$ translationally controlled tumor-associated protein p23fyp from Schizosaccharomyces pombe. J Biomol NMR 2000; 16: 83-84.

22. Lowther WT, Weissbach H, Etienne F, Brot N, Matthews BW. The mirrored methionine sulfoxide reductases of Neisseria gonorrhoeae pilB. Nat Struct Biol 2002; 9: 348-352.

23. Elkins P, Bunker A, Cramer WA, Stauffacher CV. A mechanism for toxin insertion into membranes is suggested by the crystal structure of the channel-forming domain of colicin E1. Structure 1997; 5: 443-458.

24. Minn AJ, Velez P, Schendel SL, Liang H, Muchmore SW, Fesik SW et al. Bcl-x(L) forms an ion channel in synthetic lipid membranes. Nature 1997; 385: 353-357.

25. Muchmore SW, Sattler M, Liang H, Meadows RP, Harlan JE, Yoon HS et al. X-ray and NMR structure of human Bcl-xL, an inhibitor of programmed cell death. Nature 1996; 381 335-341.

26. Schendel SL, Xie Z, Montal MO, Matsuyama S, Montal M et al. Channel formation by antiapoptotic protein Bcl-2. Proc Natl Acad Sci USA 1997; 94: 5113-5118.

27. Matsuyama S, Schendel SL, Xie Z, Reed JC. Cytoprotection by BCl-2 requires the pore-forming alpha5 and alpha6 helices. J Biol Chem 2005; 273: 30995-31001.

28. Cartron PF, Arokium H, Oliver L, Meflah K, Manon S, Vallette FM. Distinct domain control the addressing and the insertion of Bax into mitochondria. J Biol Chem 1998; 280 10587-10598.

29. Eskes R, Desagher S, Antonsson B, Martinou JC. Bid induces the oligomerization and insertion of Bax into the outer mitochondrial membrane. Mol Cell Biol 2000; 20 : 929-935.

30. Amzallag N, Passer BJ, Allanic D, Segura E, Thery C, Goud B et al. TSAP6 facilitates the secretion of translationally controlled tumor protein/histamine-releasing factor via a nonclassical pathway. J Biol Chem 2004; 279: 46104-46112.

31. Amson RB, Nemani M, Roperch JP, Israeli D, Bougueleret L, Le Gall I et al. Isolation of 10 differentially expressed CDNAs in p53-induced apoptosis: activation of the vertebrate homologue of the drosophila seven in absentia gene. Proc Natl Acad Sci USA 1996; 93 3953-3957.

32. Cans C, Passer BJ, Shalak V, Nancy-Portebois V, Crible V, Amzallag $\mathrm{N}$ et al. Translationally controlled tumor protein acts as a guanine nucleotide dissociation inhibitor on the translation elongation factor eEF1A. Proc Natl Acad Sci USA 2003; 100 13892-13897.

33. Nuoffer C, Wu SK, Dascher C, Balch WE. Mss4 does not function as an exchange factor for Rab in endoplasmic reticulum to Golgi transport. Mol Biol Cell 1997; 8 1305-1316.

34. Chen SH, Wu PS, Chou CH, Yan YT, Liu H, Weng SY et al. A knockout mouse approach reveals that TCTP functions as an essential factor for cell proliferation and survival in a tissue- or cell type-specific manner. Mol Biol Cell 2007; 18: 2525-2532.

35. Otwinowski Z, Minor W. Processing of X-ray diffraction data collected in oscillation mode. Methods Enzymol 1997; 276: 307-326.

36. Collaborative Computational Project. The CCP4 suite: programs for protein crystallography. Acta Crystallogr D Biol Crystallogr 1994; 50: 760-763.

37. Brunger AT, Adams PD, Clore GM, DeLano WL, Gros P, Grosse-Kunstleve RW et al. Crystallography \& NMR system: A new software suite for macromolecular structure determination. Acta Crystallogr D Biol Crystallogr 1998; 54 (Part 5): 905-921.

38. Kleywegt GJ, Jones TA. Efficient rebuilding of protein structures. Acta Cryst 1996; D52 829-832.

39. Laskowski RA, Mac Arthur MW, Moss DS, Thornton JM. PROCHECK: a program to check the stereochemical quality of protein structure. J Appl Crystallogr 1993; 26: 283-291.

40. Wodak SJ, Pontius J, Vaguine A, Richelle J. Validating Protein Structures. From Consistency Checking to Quality Assessment. SERC Daresbury Laboratory: Warrington, UK, 1995. 